\title{
VHF and L-band scintillation characteristics over an Indian low latitude station, Waltair $\left(17.7^{\circ} \mathrm{N}\right.$, 83.3 $\left.^{\circ} \mathrm{E}\right)$
}

\author{
P. V. S. Rama Rao, S. Tulasi Ram, K. Niranjan, D. S. V. V. D. Prasad, S. Gopi Krishna, and N. K. M. Lakshmi \\ Space Physics Laboratories, Department of Physics, Andhra University, Visakhapatnam 530 003, India
}

Received: 30 April 2005 - Revised: 6 August 2005 - Accepted: 10 August 2005 - Published: 14 October 2005

\begin{abstract}
Characteristics of simultaneous VHF (244 MHz) and L-band $(1.5 \mathrm{GHz})$ scintillations recorded at a lowlatitude station, Waltair $\left(17.7^{\circ} \mathrm{N}, 83.3^{\circ} \mathrm{E}\right)$, during the low sunspot activity year of March 2004 to March 2005, suggest that the occurrence of scintillations is mainly due to two types, namely the Plasma Bubble Induced (PBI), which maximizes during the post sunset hours of winter and equinoctial months, and the Bottom Side Sinusoidal (BSS) type, which maximizes during the post-midnight hours of the summer solstice months. A detailed study on the spectral characteristics of the scintillations at both the frequencies show that the post-sunset scintillations are strong with fast fading $(\approx 40 \mathrm{fad} / \mathrm{min})$ and are multiple in nature in scattering, giving rise to steep spectral slopes, whereas the post-midnight scintillations, which occur mostly on the VHF signal with low fading rate $(\approx 4 \mathrm{fad} / \mathrm{min})$, are of the BSS type, often showing typical Fresnel oscillations with reduced roll off spectral slopes, indicating that the type of irregularity resembles a thin screen structure giving rise to weak scattering. Using the onset times of several similar scintillation patches across the two satellite (FLEETSAT $73^{\circ} \mathrm{E}$, INMARSAT $65^{\circ} \mathrm{E}$ ) ray paths (sub-ionospheric points are separated by $82 \mathrm{~km}$ ), the East ward movement of the irregularity patches is found to vary from 150 to $250 \mathrm{~m} / \mathrm{s}$ during the post sunset hours and decrease slowly during the post midnight hours. Further, the east-west extent of the PBI type of irregularities is found to vary from 100 to $500 \mathrm{~km}$, while that of the BSS type extend up to a few thousand kilometers.
\end{abstract}

Keywords. Ionosphere (Ionospheric irregularities; Auroral ionosphere; Electric fields and currents)

\section{Introduction}

The nighttime equatorial ionospheric F-region often shows the presence of plasma density irregularities which manifest themselves as spread-F on the ionograms, plume-like struc-

Correspondence to: P. V. S. Rama Rao

(palurirao@yahoo.com) tures in the Range-Time-Intensity (RTI) images of HF radars, intensity bite-outs in airglow intensity measurements and scintillations on amplitude, as well as the phase of VHF and UHF signals from satellites, and are commonly referred to as Equatorial Spread-F irregularities (ESF). The ESF is mostly confined to the equatorial belt of $\pm 20^{\circ}$ magnetic latitudes, encompassing the Equatorial Ionization Anomaly (EIA) region.

Woodman and Lahoz (1976) classified the irregularities observed from the Jicamarca radar data into four categories: i) isolated "plumes" extending upward into the topside Fregion; ii) a more or less continuous layer up to $100 \mathrm{~km}$ in thickness, called the "bottom side" Sp-F; iii) "valley" Sp$F$ located in isolated patches below the bottom side F-layer and the more or less continuous with "sporadic E" layer, and iv) "explosive" Sp-F, a transient phenomenon observed occasionally.

It is widely accepted that the generalized Rayleigh-Taylor (RT) instability is the prime mechanism responsible for the generation of the ESF irregularities, but this mechanism (RT) alone cannot explain the various types of irregularities that are generated in equatorial ionosphere. In fact, under the name of ESF, there could be more than one physical process, which has the production of electron density fluctuations as a common effect. They all occur in the equatorial F-region ionosphere, during the night, and are capable of producing irregularities of scale sizes ranging from several hundred kilometers to a few centimeters, which can cause spread echoes in the ionograms and scintillations of radio waves from satellites at $\mathrm{HF}$ to microwave frequencies.

Krishna Moorthy et al. (1979) classified the scintillations into two types, namely Class-I and Class-II, based on their fading rates and the association with bottom side Sp-F. They reported that the Class-I scintillations mainly occur during the pre-midnight periods with fast fading rates (fading rate $>0.1$ cycles/s) and are associated with a range type of spread$\mathrm{F}$ on Ionograms, whereas the Class-II scintillations occur around the post-midnight hours with slow fading rates (fading rate $<0.1 \mathrm{cycles} / \mathrm{s}$ ) which are associated with frequency spread on Ionograms. 
Yeh et al. (1979) and Das Gupta et al. (1983) have found that TEC-depletions, which are the signatures of plasma bubbles, are always accompanied by an amplitude scintillation of a very high intensity and fading rate. They have also reported that during the pre-midnight period, there were occasions when a series of bubbles were observed within a single scintillation patch.

Das Gupta et al. (1983) reported that, during the equinoxes the scintillation patches were numerous with short periods of tens of minutes interspersed with absolutely quiet intervals. On the other hand, the summer solstice months were characterized by scintillations with extended periods lasting for several hours during a single night.

From scintillation measurements at Huancayo $\left(12^{\circ} \mathrm{S}\right)$ Basu et al. (1986) reported that discrete amplitude scintillation patches observed were associated with plasma bubbles mostly in the post-sunset hours, while continuous scintillation events existing for longer durations were associated with Bottom Side Sinusoidal (BSS) irregularities around the postmidnight hours. It has also been reported that the frequency of occurrence of BSS irregularities maximizes in the local summer.

The objective of this paper is to present a comparative study on the PBI and BSS types of irregularities in terms of their signatures on scintillation spectra at VHF and Lband frequencies observed at Waltair $\left(8.22^{\circ} \mathrm{N}\right.$ geomagnetic latitude), a station which lies between the magnetic equator and anomaly crest in Indian sector, during the low and descending phases of the sunspot activity period (March 2004 to March 2005).

\section{Data and methodology}

Simultaneous scintillation measurements at VHF (244 MHz) and L-band $(1.5 \mathrm{GHz})$ frequencies were made from two geostationary satellites, FLEETSAT $\left(73^{\circ} \mathrm{E}\right)$ and INMARSAT $\left(65^{\circ} \mathrm{E}\right)$, respectively at the Indian low-latitude station, Waltair $\left(17.7^{\circ} \mathrm{N}, 83.3^{\circ} \mathrm{E}\right)$. The scintillation data were recorded at a sampling rate of $20 \mathrm{~Hz}$, using an online digital data acquisition system. A co-located digital Ionosonde was also in operation during the same period and the Ionograms were obtained at 15 -min intervals.

A total of 314 scintillation patches at $244 \mathrm{MHz}$ and 229 patches at $1.5 \mathrm{GHz}$ were observed during the present period of observation (March 2004 to March 2005). A careful study of the scintillation events in terms of fading rates, $\mathrm{S} 4$ indices, scintillation patch durations, power spectra and their association with range/frequency type Spread-F on ionograms, has been carried out.

Power spectra of several scintillation patches observed at $244 \mathrm{MHz}$ and $1.5 \mathrm{GHz}$ were computed using the FFT algorithm for each 2-min data segment. The spectral characteristics of the PBI type scintillations were found to be clearly different from those of the BSS type scintillations.

Further, the ray path to the INMARSAT (sub-Ionospheric co-ordinates $16.4^{\circ} \mathrm{N}, 81.8^{\circ} \mathrm{E}$ ) is inclined towards the west by $54 \mathrm{~min}\left(0.9^{\circ}\right.$ longitude $)$ with respect to that of FLEETSAT (sub-Ionospheric co-ordinates $16.4^{\circ} \mathrm{N}, 82.7^{\circ} \mathrm{E}$ ) at the effective ionospheric altitude of $350 \mathrm{~km}$, i.e. a distance of $82 \mathrm{~km}$ separates the two signal paths which facilitates the computation of zonal drift velocities (west to east) with reasonable accuracy.

\section{Results}

3.1 Spectral characteristics of scintillations of PBI irregularities

Following the observations of Basu et al. (1986), the present data is classified as the PBI type if the scintillation record shows several short duration patches with fast fading, and as the BSS type if the record shows a continuous patch lasting for several hours with low fading rates. The scintillations due to PBI irregularities are identified by their sudden/abrupt onset around the post-sunset hours with high intensity and fading rates. These scintillations generally appear as several short duration patches and were associated with range type Spread-F on the ionograms (Yeh et al., 1979; Das Gupta et al., 1983; Valladares et al., 1983; Basu et al., 1986).

Figure 1 shows an example of PBI scintillation records and the corresponding intensity (amplitude) spectra at VHF $(244 \mathrm{MHz})$ and $\mathrm{L}$-band $(1.5 \mathrm{GHz})$ frequencies on a typical night of 26 March 2004. The scintillations at VHF (Fig. 1a) are intense and almost saturated $(\mathrm{S} 4>0.6)$ and have a fast fading rate that varied between 0.75 and 0.5 cycles/s (45$30 \mathrm{fad} / \mathrm{min}$ ), whereas at the L-band (Fig. 1c) the intensity is moderate $(S 4 \approx 0.3)$ and shows a low fading rate that varies between 0.33 to 0.23 cycles/s $(20-14 \mathrm{fad} / \mathrm{min})$. The high intensity and fast fading rates of VHF scintillations are due to multiple scattering of radio waves with the wide range of irregularities that are embedded in the plasma bubbles, which are moving with high velocities, whereas the L-band frequency signal is sensitive to the small-scale irregularities, and the scattering is less intense with low fading rates. It is observed from the figure that the VHF scintillation intensity spectrum (Fig. 1b) exhibits a flat, low-frequency region and a steep roll off (slope $\mathrm{p}=-6.3$ ) in the high-frequency region, with a break around $1-2 \mathrm{~Hz}$, whereas a less steeper roll off (slope $\mathrm{p}=-3.5$ ) is observed at the L-band frequency (Fig. 1d), with a break $\left(\mathrm{f}_{B}\right)$ at $0.216 \mathrm{~Hz}$.

The temporal spectra of several scintillation patches were evaluated and it was found that the plasma bubble induced VHF scintillations exhibit a flat, low-frequency region and steep roll off (with slopes (p) between -4 and -7 ) in the high-frequency region, with a break (Fresnel break frequency, $\mathrm{f}_{B}$ ) around $1-3 \mathrm{~Hz}$. The L-band scintillation amplitude spectra exhibit power law behavior, with a break frequency of 0.1 to $0.3 \mathrm{~Hz}$, and the high frequency roll off is also less steep (slopes (p) are varies between -2.5 and -4 ), indicating that small-scale structures are embedded in the largescale structures/plasma bubbles. 
3.2 Spectral characteristics of scintillations of BSS type irregularities

During the summer solstice months of May, June, July and August 2004, the presence of the BSS type of scintillations was significant at $244 \mathrm{MHz}$, with a low fading rate (fading rate $<0.1$ cycles $/ \mathrm{s}$ or $6 \mathrm{fad} / \mathrm{min}$ ), whereas the scintillations at $1.5 \mathrm{GHz}$ were almost absent. These were found to be associated with the frequency spread on the Ionograms. The onset of these scintillations was mostly around the post-midnight hours and continued for longer durations $(>3 \mathrm{~h})$.

Figures $2 \mathrm{a}$ and $\mathrm{c}$ show typical examples of VHF scintillations due to BSS type irregularities recorded on 27 May and 22 July 2004, respectively, at $244 \mathrm{MHz}$. In Fig. 2a, scintillation started at around 01:20 $\mathrm{h}$ IST and continued until the sunrise hours (for a duration of about $260 \mathrm{~min}$ ). The corresponding S4 index was about 0.3 , and the average fading rate between $02: 00$ to $02: 30 \mathrm{~h}$ IST was 0.05 cycles $/ \mathrm{s}$ ( $3 \mathrm{fad} / \mathrm{min}$ ) and between 03:00 to $03: 30 \mathrm{~h}$ IST it was $0.066 \mathrm{cycles} / \mathrm{s}$ ( $4 \mathrm{fad} / \mathrm{min})$. Figure $2 \mathrm{~b}$ shows the power spectrum computed for a 2-min data segment at 03:06 $\mathrm{h}$ and the power law spectral index (p) determined from the slope of the best fit straight line in the frequency range $0.066-0.6 \mathrm{~Hz}$ was -3.2 . In Fig. 2c, is another example of the BSS type of scintillation which occurred on 22 July 2004, which has an S4 index of about $0.4(\approx 10 \mathrm{~dB})$ at the time of onset and it decreased as the time progressed. The average fading rates computed for the 30-min duration at various stages of this scintillation patch are indicated in the figure, along with the corresponding power spectrum (Fig. 2d shows a spectral index (p) of $-3.04)$.

It was interesting to observe the presence of a systematic modulation superimposed on the linear roll-off portion of the spectrum, known as the Fresnel oscillation in the spectra (Figs. 2b and d). The first three Fresnel minima were observed at $f_{1}, \sqrt{ } 2 f_{1}, \sqrt{ } 3 f_{1}$, where $f_{1}=0.096 \mathrm{~Hz}$ and $0.15 \mathrm{~Hz}$ in Figs. $2 b$ and d, respectively. In the present case, the Fourier spectra were evaluated for each 2-min data segment of all the scintillation patches (Figs. 2a and c), and Fresnel oscillations were observed only occasionally. The spectra shown in Figs. $2 b$ and $d$ are the best ones in which the Fresnel minima were clearly detectable, whereas in the remaining spectra the Fresnel minima are not seen distinctly.

The presence of the Fresnel oscillation in the spectra normally indicates that the irregularity is confined to a thin layer of thickness less than $100 \mathrm{~km}$. The first Fresnel minimum $\mathrm{f}_{1}=\mathrm{Vo} / \sqrt{ }(\lambda \mathrm{z})$, has been shown (Rufenach, 1971, Yeh and Liu,1982) where $\lambda$ is the wavelength of the scintillation measurement, $\mathrm{z}$ is the slant range of the observer to the irregularity layer, and $V_{o}$ is the irregularity velocity normal to the propagation path. Since the zenith angle $(\chi)$ from Waltair to the FLEETSAT $\left(73^{\circ} \mathrm{E}\right)$ is $22.7^{\circ}$, and assuming the effective height of the Ionospheric Pierce Point (IPP) as $350 \mathrm{~km}$, the slant range is $\mathrm{z}=\mathrm{IPP}$ altitude $\mathrm{x} \operatorname{Sec} \chi \approx 379.39 \mathrm{~km}$ in the present case. Thus, the computed horizontal velocities of irregularities across the signal paths are $65.57 \mathrm{~m} / \mathrm{s}$ (Fig. 2b) and $102.45 \mathrm{~m} / \mathrm{s}$ (Fig. 2d), which were found to be well within
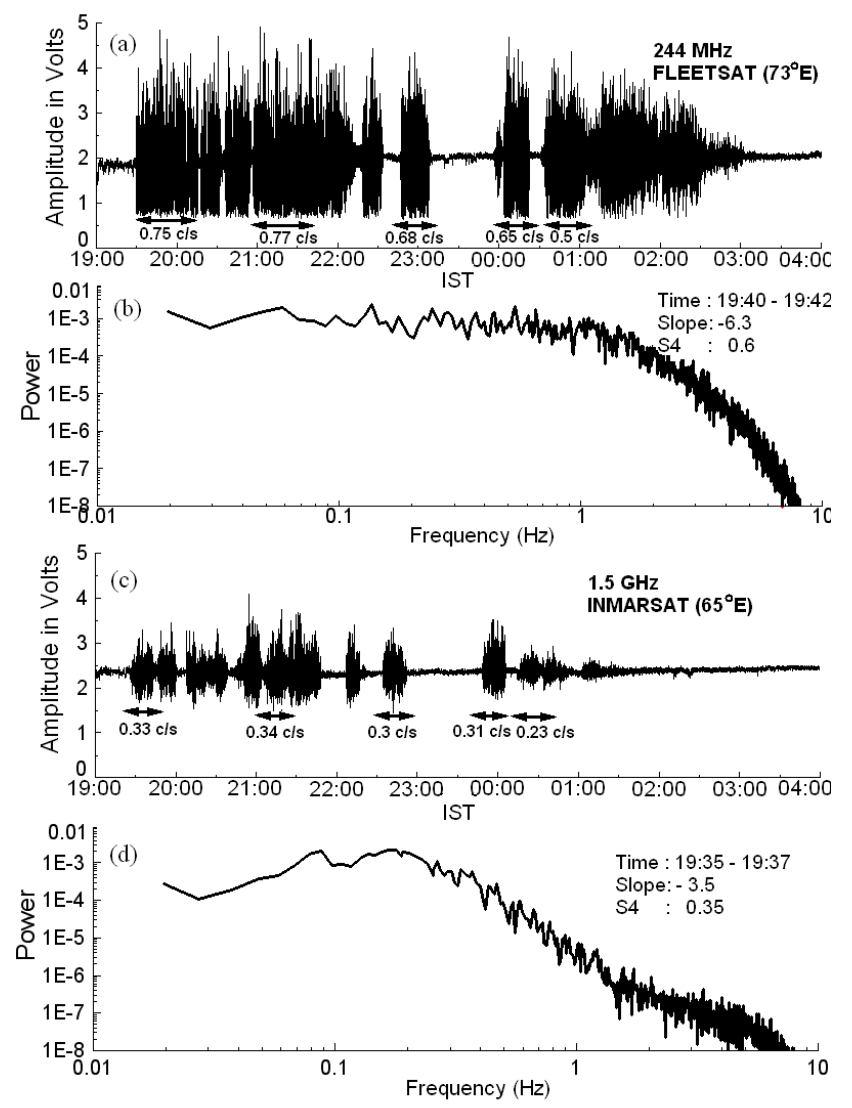

Fig. 1. (a) Typical PBI scintillation record of $244 \mathrm{MHz}$ on $26 \mathrm{March}$ 2004. (b) Power spectrum of scintillations of the record shown in Fig. 1a. (c) Typical scintillation record of $1.5 \mathrm{GHz}$ on 26 March 2004. (d) Power spectrum of scintillations of the record shown in Fig. 1c.
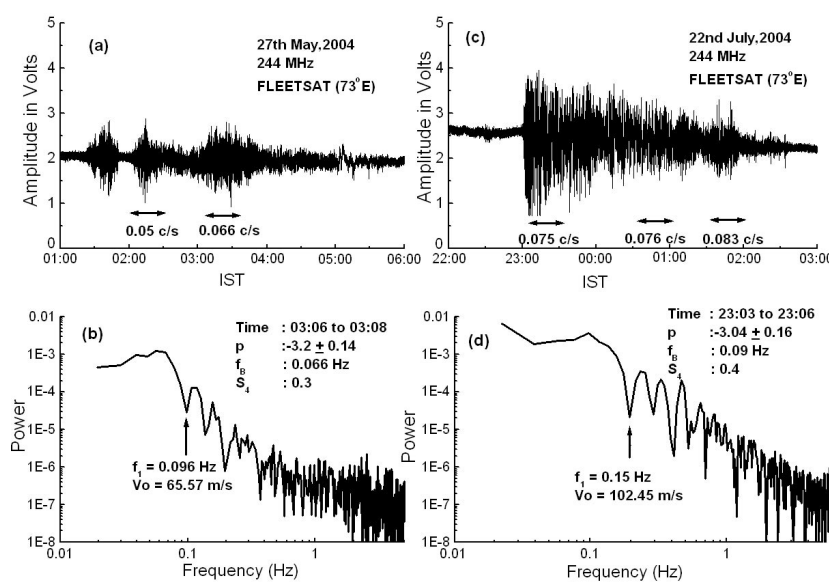

Fig. 2. (a) Typical BSS type scintillations record on 27 May 2004. (b) Power spectrum of scintillations of the above record (Fig. 2a) showing Fresnel oscillations. (c) Typical BSS type scintillations record on 22 July 2004. (d) Power spectrum of scintillations of the above record (Fig. 2c) showing Fresnel oscillations. 


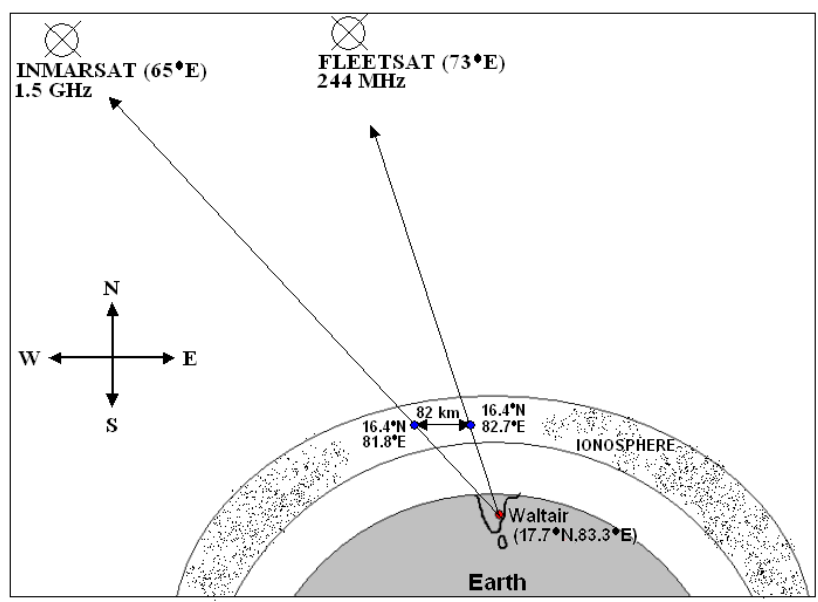

Fig. 3. Geometry of the signal paths from the two geostationary satellites (FLEETSAT, $73^{\circ} \mathrm{E}$ and INMARSAT, $65^{\circ} \mathrm{E}$ ) to the receiving station at Waltair.

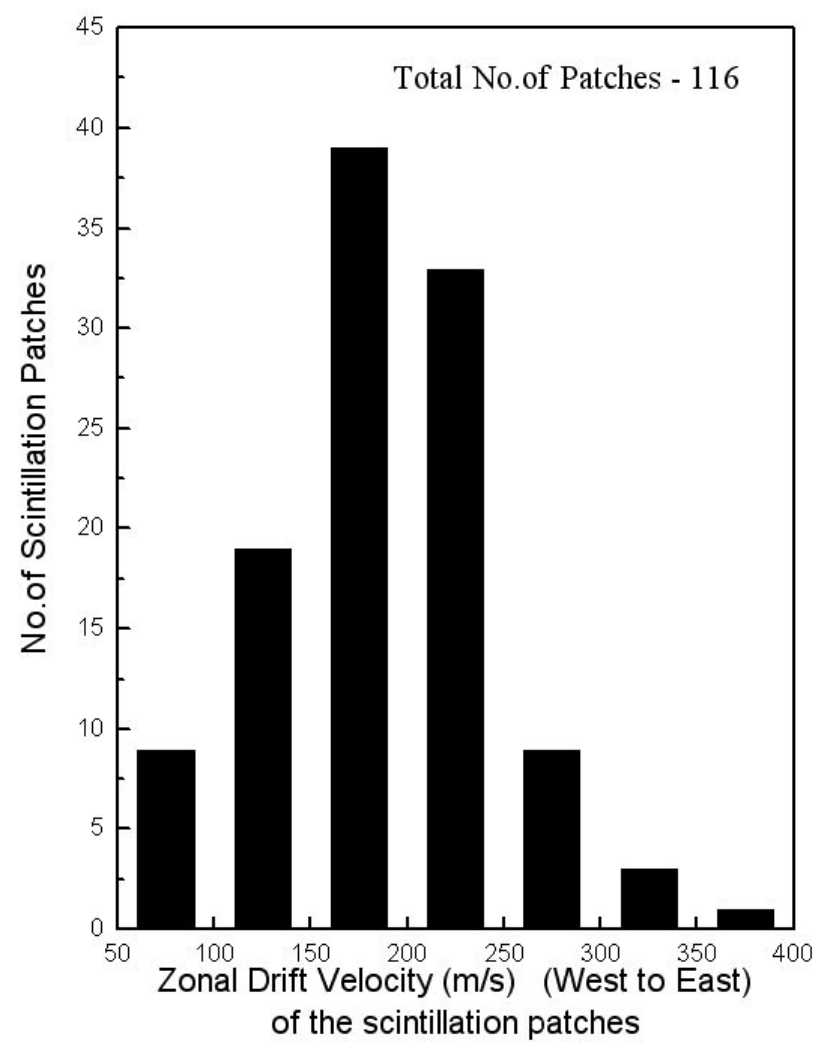

Fig. 4. Histogram showing the distribution of zonal (west to east) drift velocities of PBI irregularities.

the range of velocities reported earlier in the literature (Yeh and Liu, 1982; Franke and Liu, 1984; Basu et al., 1986; Bhattacharya et al., 2001).

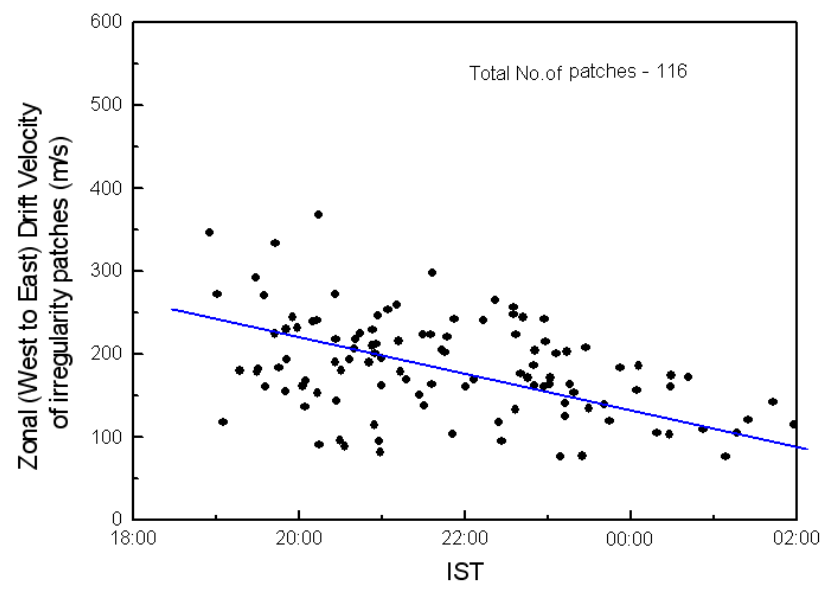

Fig. 5. Local time variation of zonal drift velocities of PBI irregularities.

\subsection{Zonal drift velocities of PBI type irregularities}

In Fig. 3, the geometry of the signal paths from the two geostationary satellites, FLEETSAT $\left(73^{\circ} \mathrm{E}\right)$ and INMARSAT $\left(65^{\circ} \mathrm{E}\right)$, and their sub-ionospheric co-ordinates is shown. The ray path to the INMARSAT is inclined towards the west by $54 \mathrm{~min}\left(0.9^{\circ}\right.$ longitude $)$ with respect to that of FLEETSAT. The ionospheric intersection points of the two paths lie on an E-W line at $350 \mathrm{~km}$ altitude and are separated by a horizontal distance of $82 \mathrm{~km}$. In most of the cases it is observed that the scintillation patches start 5 to 8 min earlier on the INMARSAT $(1.5 \mathrm{GHz})$ signal (westward) with respect to the FLEETSAT (244 MHz) signal (eastward), suggesting that the irregularities are drifting from west to east. Although there could be a frequency dependence on the onset of scintillations at the VHF and L-band frequencies, which is evaluated to be very small (Franke and Liu, 1984; Vijaykumar and Pasricha, 1996), the zonal drift velocities (west to east) of ionospheric irregularities are computed based on the exact time delay between the onset times of the scintillations at the two frequencies along the two ray paths of the satellites.

While evaluating zonal drifts, only those scintillation patches (a total of 116) having a similar structure at both VHF and L-band frequencies are considered, and the distribution of zonal drift velocities are presented in Fig. 4. It is seen from this figure that the zonal drift velocities are found to vary between 50 and $300 \mathrm{~m} / \mathrm{s}$, wherein the velocities between 150 and $250 \mathrm{~m} / \mathrm{s}$ are more probable, which is in agreement with the results reported by the earlier studies (Aarons, 1980; Franke and Liu, 1984; Vijaykumar and Pasricha, 1996; Bhattacharya, et al., 2001).

The zonal drift velocities were found to decrease slowly with local time (Fig. 5) and show a large day-to-day variability. The variation is more pronounced before $22: 00 \mathrm{~h}$ IST. These large variations in the pre-midnight period could be due to the $\boldsymbol{E} \times \boldsymbol{B}$ drifts arising from perturbation electric fields associated with equatorial plasma bubbles in the early phase of their evolution. The day-to-day variation is 

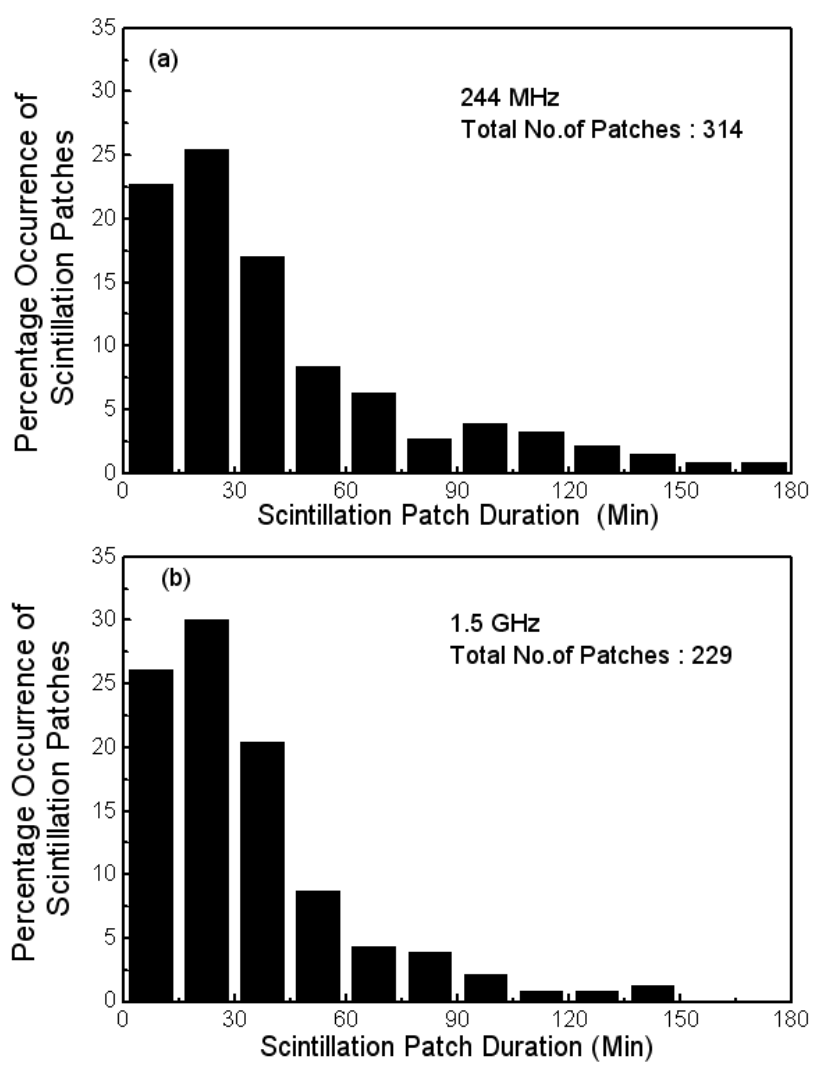

Fig. 6. Histograms showing the distribution of the patch duration of the scintillations recorded at (a) VHF and (b) L-band frequencies.

relatively small after 22:00 h IST, because the velocity structures associated with perturbation electric fields in the equatorial F-region are eroded in a couple of hours after the irregularities are initiated, while the density structures associated with scintillation-producing irregularities continue to exist for several hours longer and move with the ambient plasma drift (Bhattacharya et al., 2001).

\subsection{Patch durations and east-west extent (size) of PBI ir- regularities}

The patch durations of scintillations are mostly similar at both the frequencies, as may be seen from Fig. 6 . The duration of these patches were found to vary between 5 and $150 \mathrm{~min}$, in which the occurrences of scintillation patches with durations of 10 to $45 \mathrm{~min}$ are more probable. The total number of patches observed at $244 \mathrm{MHz}$ is higher (314) than that at $1.5 \mathrm{GHz}$ (229) because, on many occasions the PBI scintillation patches during the post-midnight hours are absent at the L-band frequency.

Combining the data of zonal drift velocities derived from the 116 patches and the patch durations of these scintillations, the size in the east-west extent of the irregularities is computed using the simple relation: $\mathrm{E}-\mathrm{W}$ extent=zonal drift velocity $\mathrm{x}$ patch duration, assuming that the irregularity structure will not change much within such a short durations

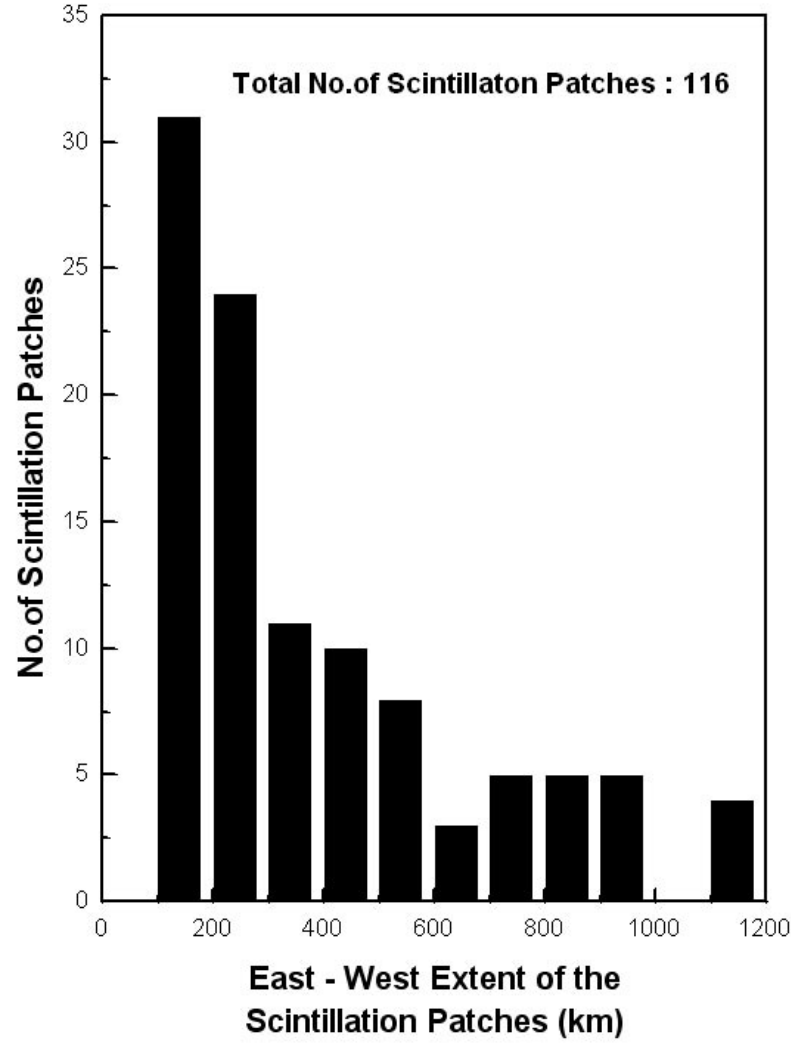

Fig. 7. Histogram showing the distribution of size (East-West extent) of PBI irregularities.

of 5 to 8 min (Rama Rao et al.; 2000). The size distribution of these irregularities is presented in Fig. 7. It may be observed from this figure that the size (E-W extent) of the irregularities varied from 100 to $1200 \mathrm{~km}$, wherein the patches with east-west extent of 100 to $500 \mathrm{~km}$ were most numerous. Thus, the east-west extent of 100 to $500 \mathrm{~km}$ results in large axial ratios, where irregularities stretched more in the northsouth direction up to the anomaly crest than in the east-west direction (Aarons et al., 1980).

Similarly, considering the patch durations of 260 and 222 min of the BSS type of irregularities presented in Figs. 2a and c, respectively, and the corresponding horizontal drift velocities derived from the Fresnel oscillations, the east-west extent of the above two patches of irregularities is computed and found to be 1022.89 and $1364.63 \mathrm{~km}$, respectively. These values lie in the range of the $\mathrm{E}-\mathrm{W}$ dimensions of $1000 \mathrm{~km}$ and above as reported by Basu et al. (1986).

From the data of solar maximum period of 1979-1980 Das Gupta et al. (1983) have also reported that the east-west extent of the irregularities was found to vary from $350 \mathrm{~km}$ to $2000 \mathrm{~km}$. Since the equatorial ionospheric irregularities are elongated along the magnetic field lines (up to $\pm 15^{\circ}$ magnetic latitudes during low solar activity period), their northsouth dimensions can extend up to a few thousand kilometers. 


\section{Discussion}

The occurrence of PBI scintillations is maximum during the post-sunset hours of equinoctial months and mostly appear as several short duration patches of $10-45 \mathrm{~min}$ in duration, interspersed with quiet intervals. whereas the occurrence of scintillations due to the BSS type of irregularities maximizes around the post-midnight hours of summer solstice months (May, June, July and August) and are generally characterized by long duration patches of $3 \mathrm{~h}$ or more. Das Gupta et al. (1983) have also found from their observations at a Southern Hemispheric station, Arequipa, Peru $\left(16.4^{\circ} \mathrm{S}, 71.5^{\circ} \mathrm{W}\right.$, $9^{\circ} \mathrm{S} \mathrm{dip}$ ), that the BSS type of scintillations during December solstice existed for several hours during a single night and that the PBI scintillations occurred during the post-sunset hours of equinoxes, showing several short duration patches and were always associated with TEC depletions. Basu et al. (1986) have reported that the BSS type of scintillations recorded from the GOES-2 satellite at Huancayo during a high sunspot activity period of 1979 showed that they could exist for long durations (more than $6 \mathrm{~h}$ ) without a break.

The plasma bubbles responsible for the occurrence of PBI scintillations are very intense and can extend up to the topside F region in plume-like structures. During the sunset and post-sunset hours, the F-region ambient ionization is relatively high with steep gradients in the electron density which are responsible for the operation of generalized RayleighTaylor instabilities to operate and for the generation of irregularities of various scale sizes, ranging from several kilometers to few centimeters. These irregularities cause range type spread-F on the ionograms, strong (almost saturated) scintillations at VHF and moderate scintillations at L-band frequencies, whereas during the post-midnight hours, the Fregion ionization is relatively small; the density gradients are also less and hence the BSS type irregularities generated during the post-midnight hours are relatively weak. The density gradients are confined to thin irregularity layers in the bottom side F-region, which manifest in the form of frequency type spread-F on the ionograms, and cause moderate to intense scintillations at VHF with no signatures on microwave frequency signals (L-band). Krishna Moorthy et al. (1979) have also reported that the Class-II scintillations are basically due to irregularities of a much larger size than those responsible for Class-I scintillations. These large-scale and relatively weak irregularities are responsible for high fading periods (low fading rates) and low S4 index values in VHF scintillations with no signatures at L-band frequencies.

The amplitude spectra of the PBI scintillations at VHF exhibit a flat, low-frequency region with roll off ( $\mathrm{p} \approx-4$ to $-7)$ in the high-frequency region, with the Fresnel break frequencies $\left(\mathrm{f}_{B}\right)$ ranging from 1 to $3 \mathrm{~Hz}$, whereas the spectra of the BSS type scintillations exhibit lower Fresnel break frequencies $\left(\mathrm{f}_{B}\right)$ of $0.06-0.1 \mathrm{~Hz}$, with reduced spectral slopes $(\mathrm{p} \approx-2.5$ to -3.5$)$ in the high-frequency region. The higher values of the Fresnel Break frequencies $\left(\mathrm{f}_{B}\right)$ observed in the PBI scintillation spectra indicate that there is a significant amount of forward scattered power contributed from the smaller scale irregularities embedded in the large-scale plasma bubbles. Also, the large spectral slopes indicate that the scattering is from multiple structures from different scale sizes of irregularities during their generation and growth stages. The low values of break frequencies and the spectral slopes observed in the BSS type scintillation spectra indicate that the scattering is weak and results from a thin layer. Thus, the spectra of the BSS type scintillations show Fresnel oscillations on the roll off portion with detectable fresnel minima at $f_{1}, \sqrt{ } 2 f_{1}, \sqrt{ } 3 f_{1}$, suggesting that the irregularity vertical extent is confined to a thin layer of thickness less than $100 \mathrm{~km}$ (Rufenach, 1972). Fresnel oscillations are expected in the Fourier spectrum of scintillation based on thin-screen approximation and weak scattering theory when the diffraction pattern is elongated in one direction, having a component of motion normal to the direction of elongation, and when the spatial spectrum of electron density fluctuations is sufficiently smooth (Singleton, 1974). In the equatorial F-region, the geometry needed for Fresnel modulation always prevails, and the irregularities are elongated in the $\mathrm{N}$ $\mathrm{S}$ direction, and the resulting anisotropic pattern drifts in the E-W direction because of "superrotation" (Rishbeth, 1971; Woodman, 1972; Basu et al., 1986).

The horizontal drift velocities of the BSS type irregularities computed from the observed Fresnel minima in the power spectrum (Sect. 3.2) are low compared to the eastward drift velocities of the PBI irregularities (Sect. 3.3). The high drift velocities of the PBI irregularities are due to the presence of strong polarization electric fields during the postsunset hours, which enhances the eastward plasma drift velocity (Kelley, 1989). The BSS irregularities, which mostly occur around the post-midnight hours, drift along with the ambient plasma which reduces due to the weakening of the westward electric field (E) during the post-midnight to predawn hours.

The longer patch durations of the BSS type scintillations suggests that the BSS irregularities extend to a few thousand kilometers in the east-west direction. Valladares et al. (1983), from AE-C and AE-E satellite data, reported that the BSS irregularities are observed in the bottom side F-region at night in a narrow belt extending approximately $\pm 12^{\circ}$ from the dip equator up to $7500 \mathrm{~km}$ or more in the east-west direction, whereas from the present study, the east-west extent of the PBI irregularities were found to range from 100 to $500 \mathrm{~km}$ in the majority of the cases. From earlier studies, Aarons et al. (1980) and Rama Rao et al. (2000) have reported that the east-west extent of the irregularity patches during post-sunset hours mostly vary between $50-250 \mathrm{~km}$.

The percentage occurrence of scintillation activity at both VHF and L-band frequencies is predominantly higher during the post-sunset hours of the equinoctial months (March, April, September and October) and moderate during winter (November, December, January and February) and low during the summer solstice months (May, June, July and August), in this low and descending phase of the solar activity period of 2004-2005. The equinoctial months are mainly characterized by the peak occurrence of PBI scintillations 
with high amplitudes $(\mathrm{S} 4 \approx 0.4$ to 0.7 at $\mathrm{VHF}$ and $\mathrm{S} 4 \approx 0.2$ to 0.5 at L-band frequency) and high fading rates. It has been reported that the scintillations with $\mathrm{S} 4>0.45(>10 \mathrm{~dB})$ at the L-band frequency may seriously effect the phase channel of the GPS receivers resulting in a Loss of Lock of the signal for a short duration (Rama Rao et al., 2004). Thus, the frequently observed high intensity in amplitude scintillations ( $\mathrm{S} 4$ index >0.45) at the L-band frequency of $1.5 \mathrm{GHz}$ of INMARSAT over Waltair indicate that the probability for the Loss of Lock of the signals in the GPS receivers at the L-band frequencies will be significant even during this low sunspot activity period and is likely to increase substantially during the high sunspot activity periods that will adversely effect the trans-ionospheric communications and navigation.

\section{Summary}

Two distinct types of scintillations have been observed: namely, the Plasma Bubble Induced (PBI) and Bottom Side Sinusoidal (BSS) type during the low and descending phases of the sunspot activity period, March 2004-March 2005, from the simultaneous recording of amplitude scintillations at VHF and L-band frequencies over an Indian low-latitude station Waltair $\left(17.7^{\circ} \mathrm{N}, 83.3^{\circ} \mathrm{E}\right)$. The occurrence of PBI scintillations, which are characterized by high intensity and fast fading, is higher during the post-sunset hours of the equinoctial months and appears at both VHF and L-band frequencies. The PBI scintillations in general, appear as several short duration patches interspersed with quiet intervals and were always associated with range type Spread-F on the ionograms. The amplitude spectra of PBI scintillations at VHF exhibit a flat, low-frequency portion and steep spectral slopes ( $\mathrm{p} \approx-4$ to -7 ), with the Fresnel break frequencies $\left(\mathrm{f}_{B}\right)$ ranging from 1 to $3 \mathrm{~Hz}$, indicating multiple scatter from different scale sizes of irregularities. The zonal (westeast) drift velocities of PBI irregularities lie between 150 $250 \mathrm{~m} / \mathrm{s}$ during the post-sunset hours, which gradually decrease during the post-midnight hours, and their east-west extents (size) vary between 100 and $500 \mathrm{~km}$ in the majority of the cases. Whereas the BSS type scintillations mostly occur during the post-midnight hours of the summer solstice months at the VHF signal, with practically no signatures at the L-band frequency. These are generally characterized by long duration patches $(>3 \mathrm{~h})$ with low intensity and slow fading, and are closely associated with frequency spread on the ionograms. The spectra of the BSS type scintillations exhibit Fresnel break frequencies $\left(\mathrm{f}_{B}\right)$ between 0.06 and $0.1 \mathrm{~Hz}$ with reduced spectral slopes ( $\mathrm{p} \approx-2.5$ to -3.5 ) and often exhibit Fresnel oscillations on the linear roll off portion of the spectrum, suggesting weak scattering from thin screen of irregularities. The zonal drift velocities of the BSS irregularities are relatively smaller than those of the PBI irregularities, while their east-west extents were found to extend up to a few thousand kilometers.
Acknowledgements. This research work presented in this paper was carried out with financial support provided by Earth System Science (ESS) Division of Department of Science and Technology (DST), New Delhi. Two of the authors (STR, NKML) express their sincere thanks for the fellowships provided to them by the DST. The authors also wish to express their sincere thanks to B. M. Reddy, B. V. Krishna Moorthy, A. Das Gupta, C. R. Reddi for useful discussions on various aspects of this paper.

Topical Editor U.-P. Hoppe thanks H. J. Strangeways and another referee for their help in evaluating this paper.

\section{References}

Aarons J., Mullen, J. P., Whitney, H. E., and Mackenzie, E. M.: The Dynamics of Equatorial Irregularity Patch Formation, Motion and Decay, J. Geophys. Res., 85, 139-149, 1980.

Bhattacharya, A., Basu, S., Groves, K. M., Valladares, C. E., and Sheehan, R.: Dynamics of equatorial $F$ region irregularities from spaced receiver scintillation observations, Geophys. Res. Lett., 28, 119-122, 2001.

Basu S., Basu Su, Valladares, C. E., Das Gupta, A., and Whitney, H. E.: Scintillations associated with bottomside sinusoidal irregularities in the equatorial F-region, J. Geophys. Res., 91, 270276, 1986.

Basu S., Valladares, C. E., Basu Su, Hanson, W. B., Kudeki, E., Swartz, W. E., and Woodman, R. F.: Multi technique irregularity and drift measurements near Jicamarca. Inter. Symp. Equatorial Aeronomy, 191-199, 1990.

Das Gupta, A., Santimay Basu, Aarons, J., Klobuchar, J. A., Sunanda Basu and Bushby, A.: VHF amplitude scintillations and associated electron content depletions as observed at Arequipa, Peru, J. Atm. Terr. Phys, 45, 15-26, 1983.

Franke, S. J., and Liu, C. H.: Observations and modeling of multifrequency VHF and $\mathrm{GHz}$ scintillations in the equatorial region, $\mathrm{J}$. Geophys. Res., 88, 7075-7085, 1983.

Franke, S. J., Liu, C. H., and McClure, J. P.: Interpretation and modeling of quasi-periodic diffraction patterns observed in equatorial VHF scintillation due to plasma bubbles, J. Geophys. Res., 89, 891-902, 1984

Krishna Moorthy, K., Ragha Reddi, C., and Krishna Moorthy, B. V.: Night-time ionospheric scintillations at the magnetic equator, J. Atm. Terr. Phys, 41, 123-134, 1979.

Kelley, M.C.: The Earth's Ionosphere, Academic press, San Diego, 1989.

Singleton, D. G.: Power spectra of ionospheric scintillations, J. Atmos. Terr. Phys., 36, 113-133, 1974.

Rama Rao, P. V. S., Ramana Rao, B. V., and Prasad, D. S. V. V. D.: A study on the zonal movements of ionospheric irregularities using two simultaneous geo-stationary signals, Indian. J. Radio and Space Physics, 29, 66-70, 2000.

Rama Rao, P. V. S., Niranjan, K., Prasad, D. S. V. V. D., Gopi Krishna, S. and Tulasi Ram, S.: Simultaneous Observations of VHF and L-band Scintillations from an Indian Low Latitude Station, Waltair $\left(17.7^{\circ} \mathrm{N}, 83.3^{\circ} \mathrm{E}\right)$, Proc. of IBSS-2004, Trieste, Italy, 2004.

Rishbeth, H.: Polarization fields produced by winds in the equatorial F-region, Planet Space. Sci., 19, 357-369, 1971.

Rufenach, C. L.: Power law wave number spectrum deduced from ionospheric scintillation observations, J. Geophys. Res., 77, 4761-4772, 1972 
Valladares, C. E., Hanson, W. B., McClure, J. P., and Cragin, B. L.: Bottomside sinusoidal irregularities in the equatorial $\mathrm{F}$ region, $\mathrm{J}$. Geophys. Res., 88, 8025-8042, 1983.

Vijaykumar, P. N. and Pasricha, P. K.: Parameterization of spectra of plasma bubble induced VHF satellite scintillations and its geophysical significance, Ann. Geophys., 15, 345-354, 1996,

SRef-ID: 1432-0576/ag/1997-15-345.

Woodman, R. F.: East-West ionospheric drifts at the magnetic equator, Space Res., 12, 969-974, 1972.
Woodman, R. F. and Lahoz, C.: Radar observations of F-region equatorial irregularities, J. Geophys. Res., 81, 5447-5466, 1976.

Yeh, K. C. and Liu, C. H.: Radio wave scintillations in the ionosphere, Proc. IEEE, 70, 324-360, 1982.

Yeh, K. C., Soicher, H., Liu, C. H., and Borelli, E.: Ionospheric bubbles observed by the Faraday rotation method at Natal, Brazil, Geophys. Res. Lett., 6, 473-475, 1979. 